\title{
Assessing the Prevalence of Orthorexia Nervosa in a Sample of University Students Using Two Different Self-Report Measures
}

\author{
María Laura Parra-Fernández ${ }^{1}\left(\mathbb{D}\right.$, María Dolores Onieva-Zafra ${ }^{1, *(\mathbb{D}}$, Elia Fernández-Martínez ${ }^{2} \mathbb{( D}$, \\ Ana Abreu-Sánchez ${ }^{2}$ and Juan José Fernández-Muñoz ${ }^{3}$ \\ 1 Department of Nursing, Physiotherapy and Occupational Therapy, Faculty of Nursing of Ciudad Real, \\ Universidad de Castilla-La-Mancha, 13071 Ciudad Real, Spain \\ 2 Department of Nursing, University of Huelva, 21004 Huelva, Spain \\ 3 Department of Psychology, University Rey Juan Carlos, 28922 Alcorcón, Madrid, Spain \\ * Correspondence: mariadolores.onieva@uclm.es; Tel.: +34-926295300
}

Received: 3 June 2019; Accepted: 9 July 2019; Published: 11 July 2019

\begin{abstract}
In recent decades, orthorexia nervosa $(\mathrm{ON})$ has increased presence in society. It is related with beliefs and attitudes towards eating and is characterized by an obsessive behavior toward heathy eating. The prevalence of $\mathrm{ON}$ has been reported by numerous researchers, with rates varying considerably according to the tool used to evaluate the same parameter. The aim of this study was to compare the prevalence of $\mathrm{ON}$ in a single population using two different questionnaires. The test for the diagnosis of orthorexia (ORTO-11-ES) assessment tool for orthorexia nervosa and the Düsseldorfer Ortorexie Skala (DOS-ES), constitute brief self-report assessment tools which measure the risk of suffering ON. A sample of 492 students from the University of Castilla la Mancha (Spain) participated in this study, of whom $43.1 \%$ were male and $56.9 \%$ were female. The findings show that, according to the DOS-ES, only $10.5 \%$ of students displayed ON whereas, with the ORTO-11-ES, the prevalence of ON increased to $25.2 \%$. The tendency towards orthorexic behavior is more closely associated with the female gender. The Body Mass Index (BMI) had no influence on the tendency for ON. This study provides valuable information on the usefulness of both questionnaires and the possible limitations associated with the use of these tools in the general population.
\end{abstract}

Keywords: orthorexia nervosa; ORTO-11-ES; DOS-ES prevalence; university students

\section{Introduction}

Orthorexia nervosa $(\mathrm{ON})$ is a behavior where affected individuals demonstrate an obsession for healthy eating, causing or potentiating damage to the individual on a physical, psychological, and social level. Individuals with $\mathrm{ON}$ experience an obsessive-compulsive behavior in the selection, planning, purchase, preparation, and consumption of healthy food, associating healthy properties to certain foods, which may have preventive or healing properties for certain illnesses [1].

Although the scientific community has not yet agreed on definitive diagnostic criteria, some authors have attempted a clarification. Notwithstanding, no consensus has been reached, to date, regarding an absolute definition of $\mathrm{ON}$ [1-3]. While certain authors have suggested classifying $\mathrm{ON}$ as a different and independent disorder, others have related it with eating and obsessive-compulsive disorders, whereas others point to similarities with autism spectrum disorders [4-6]. To date, $\mathrm{ON}$ is not included with a specific diagnosis in the primary mental health manual, the Statistical Manual of Mental Disorders (DSM-V) [7], nor in the tenth edition of the International Classification of Diseases (ICD-10) [8]. Furthermore, current research in the field of ON has mainly focused on researching 
the prevalence among different populations, which is variable depending on the respective country, the selected population, and the tool used [9-11]. Some authors have attributed these variations in the informed ranges to sociocultural differences between countries [12,13], problems in the formulation of the items in the different tools $[14,15]$, and variability in the cut-off rates in the different adaptations due to differences in language $[14,16]$. However, what is most questioned, currently, is the need to differentiate individuals who eat healthy foods in a normalized manner from those who truly have a problem with this type of eating, taking it to unhealthy extremes $[1,17]$.

What the scientific community has clarified is the need to use reliable and validated tools, as these are essential for measuring the prevalence rate, estimating risk indexes, and formulating public health recommendations for specific groups. To identify people with $\mathrm{ON}$, several questionnaires have been published, to date. The Orthorexia Self-Test was developed by Bratman and the Bratman Orthorexia Scale (BOT) was the first scale used to measure the risk of ON [18]. Thereafter, and based on this scale, the test for the diagnosis of orthorexia (ORTO-15) [9] was created and validated by Donini et al. in an Italian population. This study reported the first prevalence rates which equaled $6.8 \%$ of individuals at risk of suffering ON. To date, this tool, in its various versions, is the most commonly used by the scientific community. The ORTO-15 has been validated and adapted to different languages revealing different factor-structure models [10,16,19-21]. In these studies, the reported prevalence varies, from rates considering $17 \%$ of students at risk of ON using the ORTO-11-ES [22] to up to $36.9 \%$ in Turkey based on the ORTO-11 [23]. The most recent tool is the Düsseldorf Orthorexia Scale (DOS) [11] created by Barthels et al. in a German population, where the psychometric aspect showed good results regarding reliability and validity measurements. This scale has also been recently validated in the United States, China, and Spain [13,24,25]. In Germany, Depa et al. [26] used the DOS and reported prevalence rates of $3.3 \%$ of people with $\mathrm{ON}$ and $9.0 \%$ of people at risk of developing ON among German university students, while in the EEUU the prevalence rate was $8 \%$ of ON and $12.4 \%$ of people were at risk [24]. In Spain, we found that the adaptation and validation of both scales performed by Parra et al. [14,27], had good psychometric properties.

If we compare the results of the prevalence reported in other countries using both questionnaires, major differences can be observed in the informed ranges. In the US, Dunn et al. found a prevalence rate of $71 \%$ with the ORTO-15 [28], whereas another US study performed by Chard et al. using the DOS scale found a prevalence of $8.0 \%$ of students with ON, with an additional $12.4 \%$ considered at risk of developing ON [24]. Likewise, in Germany, variable prevalence rates were reported, ranging from $69.7 \%$ with the ORTO to $3.3 \%$ with the DOS.

Most research to date has been performed on university students, including the validation studies concerning these tools. Indeed, university students are a homogeneous sample that can be easily accessed by researchers. Additionally, university students begin their adult life away from their home, having to adopt and/or adapt to changes which include new lifestyles and which in many cases can have different influences, placing this population at risk of suffering different disorders related to their lifestyle. A number of studies suggest that a curriculum specifically directed at improving students' knowledge of nutrition could lead to a greater tendency to develop ON $[16,29,30]$. No previous research has investigated the prevalence in the same population using both questionnaires. The hypothesis of this study is that the prevalence of ON detected in a population of Spanish university students differs according to whether we apply the ORTHO-11-ES [14] or the DOS-ES [25] tools.

\section{Materials and Methods}

\subsection{Ethical Approval}

The study protocol was approved by the ethics committee of the General University Hospital of Ciudad Real (Spain) (number C-240). 


\subsection{Participants and Procedure}

The participants were recruited from the Ciudad Real campus within the Castilla La Mancha University in Spain. The selected students were studying for degrees in health science, engineering, or architecture. The inclusion criteria consisted of participants who were enrolled at the university in the year 2017/2018. There were no exclusion criteria. The data were gathered via the internet using the JotForm platform and the students voluntarily enrolled in the study. In total, 640 students were asked to complete the online questionnaire developed by the authors, with a response rate of $70.28 \%$. The analyses were focused on a sample of 492 students. In total, $43.1 \%$ students were male and $56.9 \%$ were female, with an age range from 18 to 44 years and an average age of 19.97 years $(\mathrm{SD}=3.03)$. The mean Body Mass Index was $22.64(\mathrm{SD}=6.59)$. The students came from two university faculties, health sciences $(63.8 \%)$ and engineering $(36.2 \%)$.

\subsection{Instruments}

\subsubsection{Demographic Information}

The sociodemographic forms gathered information on the age, gender, height, and weight of participants. The BMI of each participant was calculated based on the self-reported height and weight.

\subsubsection{The Spanish Version of the Düsseldorfer Orthorexie Skala (DOS-ES)}

The DOS questionnaire was originally created by Barthels et al. [24]. This scale comprised ten items about health and eating behavior. Responses are based on a four-point Likert scale where $1=$ never, $2=$ rarely, $3=$ often, and $4=$ always. The internal consistency of the original scale was 0.83 . This scale was validated in Spanish and the psychometric properties were deemed adequate. The internal consistency for the Spanish version was 0.841 . The range of scores was between 10 and 40 points. The cut-off point was $\geq 30$ points in order to label people with orthorexia nervosa (ON) [25].

\subsubsection{The ORTO-11-ES Questionnaire}

The ORTO-15 questionnaire was originally developed in Italian [9]. This tool consists of 15 self-report multiple choice items using a 4-point Likert-type scale (always, often, sometimes, never) to measure three underlying factors related to eating behavior: Cognitive-rational (items 1,5, 6, 11, 12 , and 14), clinical (items $3,7,8,9$, and 15), and emotional aspects (items 2, 4, 10, and 13). It is used to investigate obsessive behavior related to the selection and preparation of food, habits of food consumption, and attitudes toward healthy food. The lower the score, the higher the indication of a behavior or attitude related to orthorexia. The Italian group [9] suggested a cut-off score of 40 points, whereby scores below this figure indicated ON-related behavior. For the present study, we used the ORTO-11-ES [14] as a tool for assessing ON. This tool is based on a structure of three factors for the abbreviated 11-item version and demonstrates an appropriate internal consistency (Cronbach's alpha $=0.80$ ). Furthermore, the test demonstrated a good predictive capacity for a threshold value of $<25$ (79.5\% effectiveness, $75 \%$ sensitivity, and $79.6 \%$ specificity).

\subsubsection{The Eating Disorder Inventory-EDI-2-Spanish Version}

The Eating Disorder Inventory (EDI-2) is a self-reported 91-item questionnaire, answered on a six-point Likert-Type-Scale, using a three-point system where "sometimes", "rarely", and "never", are assigned zeros, while "often", "usually" and "always" are assigned a score of 1, 2, or 3, respectively. The questionnaire is used to assess eating-disorder symptoms, attitudes, and behaviors. It contains 11 subscales: Drive for thinness, body satisfaction, bulimia, effectiveness, perfectionism, interpersonal disruption, interceptive awareness, maturity fears, asceticism, impulse regulation, and social insecurity. The sub-scale scores can be calculated by simply adding the scores of all the items of each specific 
sub-scale. The EDI-2 total score ranges from 91 to 546 . We used a Spanish version of the scale validated by Corral, Pereña, and Seis-dedos in 1999, which showed an internal consistency of 0.83-0.92 [31].

The EDI-2 is a widely used tool in Spain. The validity of this tool has been proven for its accuracy in the detection and diagnosis of the risk of developing eating disorders among the Spanish population [32]. In this study, the EDI-2 was used based on its good psychometric proprieties in both clinical settings and non-clinical samples [33], as well as the ability to evaluate different dimensions [34].

\subsection{Analysis}

The statistical analyses were applied with SPSS 25.0 (IBM, Armonk, NY, USA). The $\chi^{2}$ test was developed with gender, Body Mass Index (BMI), type of studies, and DOS and ORTO. BMI was structured in several levels: $<18.5$ was underweight, between 18.5 and 24.9 was normal, between 25.0 and 29.9 was overweight, and finally, $\geq 30$ was obese. Crosstabs were performed with the percentage of each cell.

Regarding the DOS, the authors applied a cutoff score of 30 points. In the case of the ORTO-11-ES, the cutoff score was less than 25 points [14]. The two sample $t$-test is a statistical procedure in order to compare the means in two independent groups. In this study, the dependent variables were the subscales of EDI-2. The Kolmogorov Smirnov test showed that all dependent variables fit a normal distribution $(p>0.05)$. The variables of DOS and ORTO were calculated and included the two sample $t$-test as independent variables. The relationships between the variables were statistically significant $(p$ value $<0.05)$.

\section{Results}

\subsection{Prevalence of Orthorexia with DOS-ES and ORTO-11-ES}

The average score of the DOS scale was 17.52 (SD = 5.16) with a range of 10-38. The cutoff point for this scale was $>30$, or more, according to the 95th percentile. In this sense, the results showed that only $10.5 \%$ were participants with ON while $89.4 \%$ displayed no prevalence of ON. On the other hand, according to the ORTO, $25.2 \%$ of the sample showed indications of orthorexia nervosa, with the remaining $74.8 \%$ showing no sign of orthorexia nervosa. The score average of ORTO was 28.44 $(\mathrm{SD}=5.67)$ with a range of $12-44$ (see Table 1$)$.

Table 1. Prevalence of orthorexia according to gender, Body Mass Index (BMI), and type of studies between the Düsseldorf Orthorexia Scale (DOS) and the test for the diagnosis of Orthorexia (ORTO).

\begin{tabular}{|c|c|c|c|c|c|c|c|}
\hline \multicolumn{2}{|c|}{ Variables } & \multirow{3}{*}{$\begin{array}{c}\text { DOS (\%) } \\
4.1 \\
6.5\end{array}$} & \multirow{3}{*}{$\begin{array}{c}\text { ORTO (\%) } \\
6.7 \\
18.5\end{array}$} & \multirow{3}{*}{$\begin{array}{c}\begin{array}{c}\chi^{2} \text { Test } \\
\text { (DOS) }\end{array} \\
1.14\end{array}$} & \multirow{3}{*}{$\begin{array}{c}\boldsymbol{p} \begin{array}{c}\text { Value } \\
\text { (DOS) }\end{array} \\
0.274\end{array}$} & \multirow{3}{*}{$\begin{array}{c}\begin{array}{c}\chi^{2} \text { Test } \\
\text { (ORTO) }\end{array} \\
18.12\end{array}$} & \multirow{3}{*}{$\begin{array}{c}\boldsymbol{p} \text { Value } \\
\text { (ORTO } \\
0.00\end{array}$} \\
\hline Gender & Male & & & & & & \\
\hline Gender & Female & & & & & & \\
\hline \multirow{4}{*}{ BMI } & Underweight & 1.0 & 1.4 & \multirow{4}{*}{0.623} & \multirow{4}{*}{0.891} & \multirow{4}{*}{4.18} & \multirow{4}{*}{0.312} \\
\hline & Normal & 7.6 & 17.9 & & & & \\
\hline & Overweight & 1.6 & 4.5 & & & & \\
\hline & Obese & 0.2 & 1.4 & & & & \\
\hline \multirow{2}{*}{ Studies } & Engineering & 3.6 & 6.7 & \multirow{2}{*}{0.387} & \multirow{2}{*}{0.534} & \multirow{2}{*}{6.40} & \multirow{2}{*}{0.04} \\
\hline & Health Sciences & 6.9 & 18.5 & & & & \\
\hline
\end{tabular}

\subsection{Differences between Orthorexia and Subscales of EDI-2}

Table 2 shows the Analysis of Variance (ANOVA) between subscales of EDI-2 and the prevalence according to the DOS. In this sense, there were significant differences in the following subscales: Drive for thinness $(\mathrm{F}(2,491)=16.90, p<0.01)$, body dissatisfaction $(\mathrm{F}(2,491=3.50, p<0.05)$, perfectionism $(\mathrm{F}(2,491=4.83, p<0.01)$, interceptive awareness $(\mathrm{F}(2,491=3.83, p<0.05)$, and asceticism $(\mathrm{F}(2,491=13.54, p<0.01)$. 
Table 2. Analysis of Variance between (DOS) and subscales of the Eating disorder Inventory (EDI-2).

\begin{tabular}{|c|c|c|c|c|c|}
\hline Subscales of the Eating Disorder Inventory & DOS & $\mathbf{N}$ & $\mathbf{M}$ & SD & F \\
\hline \multirow{3}{*}{ Drive for thinness } & Up to 24 & 440 & 13.91 & 8.31 & \multirow{3}{*}{16.90 * } \\
\hline & $25-29$ & 41 & 20.22 & 8.03 & \\
\hline & Greater than or equal to 30 & 11 & 23.27 & 8.78 & \\
\hline \multirow{3}{*}{ Body dissatisfaction } & Up to 24 & 440 & 17.09 & 9.87 & \multirow{3}{*}{$3.50 * *$} \\
\hline & $25-29$ & 41 & 20.59 & 11.21 & \\
\hline & Greater than or equal to 30 & 11 & 22.27 & 14.63 & \\
\hline \multirow{3}{*}{ Perfectionism } & Up to 24 & 440 & 14.26 & 5.83 & \multirow{3}{*}{4.83 * } \\
\hline & $25-29$ & 41 & 16.46 & 5.46 & \\
\hline & Greater than or equal to 30 & 11 & 18.09 & 5.37 & \\
\hline \multirow{3}{*}{ Interceptive awareness } & Up to 24 & 440 & 16.85 & 8.63 & \multirow{3}{*}{$3.83 * *$} \\
\hline & $25-29$ & 41 & 19.44 & 9.20 & \\
\hline & Greater than or equal to 30 & 11 & 22.55 & 6.74 & \\
\hline \multirow{3}{*}{ Asceticism } & Up to 24 & 440 & 12.53 & 5.41 & \multirow{3}{*}{13.54 * } \\
\hline & $25-29$ & 41 & 16.27 & 6.02 & \\
\hline & Greater than or equal to 30 & 11 & 18.09 & 6.70 & \\
\hline
\end{tabular}

Table 3 shows the two-sample $t$-test between subscales of EDI-2 and the prevalence according to the ORTO. In this sense, there were significant differences in the following subscales: Drive for thinness $(t(1,489)=10.24, p<0.01)$, bulimia $(t(1,489)=4.19, p<0.01)$, body dissatisfaction $(t(1,489)=6.61$, $p<0.01)$, perfectionism $(t(1,490)=2.92, p<0.01)$, effectiveness $(t(1,489)=2.74, p<0.01)$, interceptive awareness $(t(1,489)=4.84, p<0.01)$, asceticism $(t(1,489)=4.93, p<0.01)$, and impulse regulation $(t(1,489)=3.13, p<0.01)$. Obviously, in all cases the higher numbers related to the people with ON.

Table 3. Two sample $t$-test for differences of means (ORTO) between subscales of EDI-2.

\begin{tabular}{|c|c|c|c|c|c|}
\hline Subscales of the Eating disorder Inventory & ORTO * & $\mathbf{N}$ & $\mathbf{M}$ & SD & $t$ test \\
\hline \multirow{2}{*}{ Drive for thinness } & with ON & 124 & 20.79 & 7.82 & \multirow{2}{*}{$t(1,489)=10.11, p<0.01$} \\
\hline & without ON & 367 & 12.60 & 7.77 & \\
\hline \multirow{2}{*}{ Bulimia } & with ON & 124 & 10.95 & 6.79 & \multirow{2}{*}{$t(1,489)=4.49, p<0.01$} \\
\hline & without $\mathrm{ON}$ & 367 & 8.25 & 5.41 & \\
\hline \multirow{2}{*}{ Body dissatisfaction } & with ON & 124 & 22.65 & 10.81 & \multirow{2}{*}{$t(1,489)=6.80, p<0.01$} \\
\hline & without ON & 367 & 15.79 & 9.31 & \\
\hline \multirow{2}{*}{ Perfectionism } & with ON & 124 & 15.41 & 6.39 & \multirow{2}{*}{$t(1,490)=2.92, p<0.01$} \\
\hline & without ON & 367 & 14.25 & 5.62 & \\
\hline \multirow[b]{2}{*}{ Effectiveness } & with ON & 124 & 15.57 & 9.31 & \multirow{2}{*}{$t(1,489)=1.92, p<0.01$} \\
\hline & without ON & 367 & 13.32 & 7.97 & \\
\hline \multirow{2}{*}{ Interceptive awareness } & with ON & 124 & 20.27 & 8.91 & \multirow{2}{*}{$t(1,489)=4.60, p<0.01$} \\
\hline & without ON & 367 & 16.20 & 8.36 & \\
\hline \multirow{2}{*}{ Asceticism } & with ON & 124 & 14.74 & 5.93 & \multirow{2}{*}{$t(1,489)=4.11, p<0.01$} \\
\hline & without ON & 367 & 12.37 & 5.41 & \\
\hline \multirow{2}{*}{ Impulse regulation } & with ON & 124 & 17.10 & 9.33 & \multirow{2}{*}{$t(1,489)=3.2 .38, p<0.05$} \\
\hline & without ON & 367 & 14.91 & 8.70 & \\
\hline
\end{tabular}

* ON $=$ Orthorexia nervosa.

\subsection{Relationships between Orthorexia and EDI-2 Subscales}

Table 4 shows significant correlations with a confidence level of $p<0.01$ and $p<0.05$ between ORTO, DOS, and EDI-2 subscales. For instance, the correlation between ORTO and DOS was $(r=-0.610, p<0.01)$. Moreover, the Cronbach's alpha of the ORTO scale was $\alpha=0.841$; for the DOS it was $\alpha=0.791$. The remaining significant correlations between the ORTO, DOS, and EDI-2 subscales are displayed in Table 4. 
Table 4. Correlation matrix between ORTO, DOS, and EDI-2 subscales.

\begin{tabular}{|c|c|c|c|c|c|c|c|c|c|c|c|c|}
\hline Correlation & 1 & 2 & 3 & 4 & 5 & 6 & 7 & 8 & 9 & 10 & 11 & 12 \\
\hline \multicolumn{13}{|l|}{ 1. ORTO } \\
\hline 2. DOS & $-0.610^{* *}$ & & & & & & & & & & & \\
\hline 3. Drive for thinness & $-0.594^{* *}$ & $0.500 * *$ & & & & & & & & & & \\
\hline 4. Bulimia & $-0.243^{* *}$ & $0.195^{* *}$ & $0.347^{* *}$ & & & & & & & & & \\
\hline 5. Body dissatisfaction & $-0.390^{* *}$ & $0.288^{* *}$ & $0.719^{* *}$ & $0.384^{* *}$ & & & & & & & & \\
\hline 6. Perfectionism & $-0.162^{* *}$ & $0.176^{* *}$ & $0.091 *$ & $0.267^{* *}$ & 0.011 & & & & & & & \\
\hline 7. Effectiveness & $-0.165^{* *}$ & $0.160^{* *}$ & 0.336 ** & $0.361 * *$ & $0.460 * *$ & $0.185^{* *}$ & & & & & & \\
\hline 8. Interpersonal disruption & -0.044 & 0.029 & 0.076 & $0.223 * *$ & $0.179 * *$ & $0.162 * *$ & $0.506^{* *}$ & & & & & \\
\hline 9. Interceptive awareness & $-0.291 * *$ & $0.237^{* *}$ & $0.378 * *$ & $0.539 * *$ & $0.395^{* *}$ & $0.313^{* *}$ & $0.609 * *$ & $0.429 * *$ & & & & \\
\hline 10. Maturity fears & -0.040 & -0.007 & $0.102 *$ & $0.172^{* *}$ & $0.142^{* *}$ & $0.124^{* *}$ & $0.304^{* *}$ & $0.139 * *$ & $0.333^{* *}$ & & & \\
\hline 11. Asceticism & $-0.262 * *$ & $0.331^{* *}$ & $0.439 * *$ & $0.478^{* *}$ & $0.412^{* *}$ & $0.321^{* *}$ & $0.543^{* *}$ & $0.338 * *$ & $0.625^{* *}$ & $0.192 * *$ & & \\
\hline 12. Impulse regulation & $-0.170^{* *}$ & $0.166^{* *}$ & $0.222 * *$ & $0.464^{* *}$ & $0.221^{* *}$ & $0.310^{* *}$ & $0.466^{* *}$ & $0.307^{* *}$ & $0.623^{* *}$ & $0.251^{* *}$ & $0.590^{* *}$ & \\
\hline 13. Social insecurity & -0.075 & $0.092 *$ & $0.160 * *$ & $0.263^{* *}$ & $0.307^{* *}$ & $0.155^{* *}$ & $0.672^{* *}$ & $0.684^{* *}$ & $0.453^{* *}$ & $0.210^{* *}$ & $0.467^{* *}$ & $0.445^{* *}$ \\
\hline
\end{tabular}




\section{Discussion}

Researchers and professionals are faced with situations where they are required to choose between several potentially viable scales which are designed for measuring a certain construct. At times, it is difficult to determine, in any field, which of the scales is the most useful.

In general, our findings regarding the prevalence of $\mathrm{ON}$, based on the two questionnaires used in our sample, agree with the scientific literature published to date $[13,24,30,35,36]$, albeit with very mixed results according to the tool used. However, the distinction is that this study has been administrated to the same sample. The prevalence detected using the ORTHO-11-ES tool was noticeably higher than that detected by the DOS-ES regarding the risk of suffering orthorexia, although the DOS-ES tool enabled us to establish a varying prevalence according to whether a risk of suffering orthorexia [24] was detected. The DOS-ES therefore differed when compared to the widely used ORTO-11-ES, in that it offered a possibility of distinguishing two groups of behaviors in relation to this pathology. However, even when both values were added, i.e., those at risk and those with a prevalence of $\mathrm{ON}$, the end result remained lower than that provided by the ORTO-11-ES.

One of the causes of this disparity regarding the resulting prevalence values may be due to the psychometric properties of the ORTO-15 [9] in the different validations, as these vary depending on the country or respective translation used. The original ORTHO-15 [9] questionnaire decreased by an important number of items, changing the factorial structure in the different versions as well as the originally established cut-off point, whereas, in the DOS [24], both the 10 item structure and the established cut-off point were fully maintained by the original authors of the questionnaire. In favor of the ORTO-15 [9], we can argue that it was one of the first tools which, from its inception, attempted to provide insight into this pathology, while raising awareness in society and among scientists regarding the incipient development of $\mathrm{ON}$ in our increasingly obsessed 21st century culture of healthy eating. In addition, it is important to add that neither at that time nor to date has there been a consensus in the diagnostic criteria; therefore, the suitability of including certain items, or not, is even more complicated $[1,2,4]$.

It is important to highlight that the sociocultural differences appear as part of the discussion in many validations of these tools, especially with regard to the ORTO-15 $[37,38]$ and, more recently, the DOS. Societies exist where the cultural and/or religious beliefs mean that these populations have a well-established cultural relationship with food. In this sense, it is important to clarify that the problem in the detection of the risk of $\mathrm{ON}$ and in relation to different cultures is precisely in this fine line that separates the desire to follow a healthy diet or lifestyle from displaying an obsession for the same, which is considered a pathological approach toward eating. There are cultures which have always highly valued healthy eating as being the basis of their way of living, whereas other cultures have very different ingrained ideas regarding the subject. In China, for example, a study developed by Jinbo $\mathrm{He}$ et al. showed a prevalence of $7.8 \%$ using a validation of the DOS, with the authors assuming that the risk of $\mathrm{ON}$ in this population may be greater due to the fact that it is a culture with over 100 years of history regarding the maintenance of a healthy diet [13].

In contrast with the ORTO, the DOS is relatively new and its use is still limited to populations where the validation and translation of the same has been performed. However, both in the construction and in the psychometric properties, to date, improved results have been reported in the validation of this new tool $[13,24]$. These positive results should encourage and inspire researchers to continue this line of study in order to understand a behavior that is still undefined. It is important to remember that the tools and research used to evaluate behaviors should also support incorporating and/or evaluating the physical responses that occur in $\mathrm{ON}$, which could contribute toward a differential diagnosis $[39,40]$.

Another association which has been studied within the reported prevalence is the possible correlation of ON with gender. In our study, we observed that women are more likely to suffer ON, which correlates with other studies [12,29,41-43]. In contrast, other articles have noted a greater prevalence among men [13,21,35,44], whereas others have found no relationship [42,45-47]. All these results have led to the understanding that $\mathrm{ON}$ does not distinguish between gender. The stereotypes 
of health and beauty in the 21st century are continuously changing; the mass media bombard us and influence us in everyday decisions, including how we should eat, the way we dress, and how we take care of our body. This media onslaught does not discriminate between men and women regarding influencing lifestyles.

The present findings also reveal that the association with BMI was very low and statistically non-significant with both questionnaires, which is in line with most studies $[13,23,24,39,48]$. The greatest concern of these individuals is to maintain a healthy body, within a context of health in all its forms. Some authors have suggested that the onset of ON may be due, at times, to the beginning of diets to lose weight, meaning that when these are maintained over time, it can trigger an obsession for healthy eating in the individual [49]. The fact that a negative correlation exists between the BMI and the risk of ON has been perceived by some authors as a definitive fact for establishing this lack of relationship between ON and eating disorders (EDs) [24]. However, other authors have also found a relationship between ON with a low BMI. In a study by Gezer and Kabara [50], the risk of ON was found to be significantly greater in those with a low BMI $\left(\leq 18.5 \mathrm{~kg} / \mathrm{m}^{2}\right)$ compared with other groups; however, this data on its own should not be considered a definitive criteria for establishing a clear diagnosis, for example of anorexia nervosa (AN).

Both scales have been found to correlate with different dimensions of the EDI-2. Among the dimensions that have not been correlated with any of the questionnaires are "interpersonal disruption and maturity fears", both of which are dimensions which have less in common with the ON construct. The desire to return to the safety of infancy or the desire to publicly hide attitudes or thoughts related to a person's eating behavior are more related to other EDs. Besides, in the case of ORTO, this is not correlated with "social insecurity", which is a dimension which, besides being considered an essential trait when studying EDs, certainly is considered as being an essential trait in the assessment of ON with regard to the social isolation that it causes. In the English validation of the DOS by Chard et al. [24], all scores are minimal for these two dimensions and no correlation was found with DOS. Barthel et al. [11] only used three subscales of the EDI-2 and found correlations, although, at the same time, they used the most discussed dimensions regarding a possible relationship between other EDs and ON. These relationships have been widely discussed by a number of authors $[1-4,34]$ with the obsession for thinness being the feature most highlighted by different researchers on this subject [20,34]. The items associated with this dimension attempt to encompass the concern that the individual has for weight and diets, considering this as one of the psychological nuclei present in EDs. In the criteria established by Barthel et al. in 2015, in relation to the diagnosis of ON, weight loss or being underweight is, indeed, one of the defining criteria of $\mathrm{ON}$, with the exception that this excessive concern about weight does not always dominate the syndrome. In these cases it is recommended to assess another ED diagnosis [3]. If we consider that many authors consider ON as a subtype of AN [51], and having clearly established the relationship between obsession for thinness and anorexia or ON, the key is that the orthorexia questionnaires must provide the key to shift the balance more toward the well-established discussion between quality versus quantity of food [5]. The use of the EDI-2 is more widespread in patients with a confirmed clinical diagnosis, therefore, the use of this in patients who are lacking this clinical aspect has led to a clarification of whether some of the dimensions of certain EDs may be predictors of behavior in those that show a risk of suffering ON [52]. Therefore, further studies are required to confirm what some authors are suggesting. In this sense, the ORTHO-15 is the tool that has received most criticism to date, precisely because of the inability to distinguish between a healthy lifestyle, including lifestyles which have dietary restrictions, and behaviors that drive ON. In the case of the DOS, this tool does not demonstrate these imperfections in its psychometric properties. Furthermore, considering there are fewer studies using this tool, to date, no study has demonstrated that this may be the ideal instrument for performing a definitive screening in this population.

The field of orthorexia nervosa is rather new and it is important to have a good instrument which is able to measure both the healthy aspects (self-care) and unhealthy aspects of orthorexia nervosa. New studies along these lines support the existence of a new entity named Healthy Orthorexia (HO), 
compared to ON. These entities are not considered a continuum, rather as related, but differentiated, entities, where the dimensions related to psychopathological aspects are only present in ON and not in HO. A new questionnaire has been developed by researchers in an attempt to demonstrate the differences between people who adopt a healthy diet without evidence of obsessive behavior or any type of negative impact on their health and those who, as the definition of ON states, take this obsession to extremes which may damage their health [53,54].

The limitations of this study are mainly based on the impossibility of generalizing these results, as this study was performed on Spanish university students. A larger number of studies are required to understand the possible differences in the prevalence rates, not only regarding the application of different questionnaires but also the application of these findings to different populations, including those individuals with different dietary habits. Additionally, it is important to underline the fact that the participants used self-administered questionnaires, which may have influenced the objectivity of certain data, such as self-reported height and weight; this means the calculated BMIs based on this data may contain errors, as shown by other authors [52]. Furthermore, as this study was conducted on a university population, with their own distinct characteristics, it is impossible to extrapolate these data to the general population.

\section{Conclusions}

The different prevalence rates found with both tools lead us to affirm that the development of a comprehensive, sensitive, and valid questionnaire for assessing the symptoms of orthorexia should be supported by further studies with clinical patients, where observation and/or possible treatment measures may provide information regarding the pattern of the illness. It is important to consider that questionnaires are valuable tools for screening patients within a clinical environment, however, this does not replace the clinician's diagnostic criteria. In this sense, research must advance in both ways, i.e., by screening large populations who are susceptible to be at risk of $\mathrm{ON}$, where health measures would be valuable for prevention and in clinical practice.

Author Contributions: Conceptualization, M.D.O.-Z. and M.L.P.-F.; methodology, M.D.O.-Z., M.L.P.-F., E.F.-M., A.A.-S., and J.J.F.-M.; software M.D.O.-Z., M.L.P.-F., E.F.-M., A.A.-S., and J.J.F.-M.; validation, M.D.O.-Z., M.L.P.-F., E.F.-M., A.A.-S., and J.J.F.-M.; formal analysis, M.D.O.-Z., M.L.P.-F., and J.J.F.-M.; investigation, M.D.O.-Z., M.L.P.-F., E.F.-M., A.A.-S., and J.J.F.-M.; resources, M.D.O.-Z., M.L.P.-F., E.F.-M., A.A.-S., and J.J.F.-M.; data curation, M.D.O.-Z., M.L.P.-F., E.F.-M., and J.J.F.-M.; writing—original draft preparation, M.D.O.-Z., M.L.P.-F., and J.J.F.-M.; writing-review and editing, M.D.O.-Z., M.L.P.-F., E.F.-M., A.A.-S., and J.J.F.-M.; visualization, M.D.O.-Z., M.L.P.-F., E.F.-M., A.A.-S., and J.J.F.-M.; supervision, M.D.O.-Z., M.L.P.-F., and J.J.F.-M.; project administration, M.D.O.-Z., M.L.P.-F., E.F.-M., A.A.-S., and J.J.F.-M.

Funding: This research received no external funding.

Acknowledgments: The authors thank all the students who participated in the study for their selfless collaboration.

Conflicts of Interest: The authors declare no conflict of interest.

\section{References}

1. Dunn, T.M.; Bratman, S. On orthorexia nervosa: A review of the literature and proposed diagnostic criteria. Eat. Behav. 2016, 21, 11-17. [CrossRef] [PubMed]

2. Moroze, R.M.; Dunn, T.M.; Craig Holland, J.; Yager, J.; Weintraub, P. Microthinking about Micronutrients: A Case of Transition from Obsessions about Healthy Eating to Near-Fatal "Orthorexia Nervosa" and Proposed Diagnostic Criteria. Psychosomatics 2015, 56, 397-403. [CrossRef] [PubMed]

3. Barthels, F.; Meyer, F.; Pietrowsky, R. Orthorexic eating behavior1 A new type of disordered eating. Ernahr. Umsch. 2015, 62, 156-161. [CrossRef]

4. Cena, H.; Barthels, F.; Cuzzolaro, M.; Bratman, S.; Brytek-Matera, A.; Dunn, T.; Varga, M.; Missbach, B.; Donini, L.M. Definition and diagnostic criteria for orthorexia nervosa: A narrative review of the literature. Eat. Weight Disord. 2019, 24, 209-246. [CrossRef] [PubMed]

5. Brytek-Matera, A. Orthorexia nervosa-an eating disorder, obsessive-compulsive disorder or disturbed eating habit? Arch. Psychiatry Psychother. 2012, 1, 55-60. 
6. Knüppel, A.; Telléus, G.K.; Jakobsen, H.; Lauritsen, M.B. Quality of life in adolescents and adults with autism spectrum disorder: Results from a nationwide Danish survey using self-reports and parental proxy-reports. Res. Dev. Disabil. 2018, 83, 247-259. [CrossRef] [PubMed]

7. American Psychiatric Association. Guía de Consulta de los Criterios Diagnósticos del DSM-5 ${ }^{\circledR}$; American Psychiatric Publishing: London, UK, 2013.

8. The ICD-10 Classification of Mental and Behavioural Disorders Clinical Descriptions and Diagnostic Guidelines. Available online: http://www.who.int/classifications/icd/en/bluebook.pdf (accessed on 12 January 2019).

9. Donini, L.M.; Marsili, D.; Graziani, M.P.; Imbriale, M.; Cannella, C. Orthorexia nervosa: Validation of a diagnosis questionnaire. Eat. Weight Disord. 2005, 10, e28-e32. [CrossRef]

10. Arusoğlu, G.; Kabakçi, E.; Köksal, G.; Merdol, T.K. Orthorexia nervosa and adaptation of ORTO-11 into Turkish. Turk Psikiyatr. Derg. 2008, 19, 283-291.

11. Barthels, F.; Meyer, F.; Pietrowsky, R. Die Düsseldorfer Orthorexie Skala-Konstruktion und Evaluation eines Fragebogens zur Erfassung ortho-rektischen Ernährungsverhaltens. Z. Klin. Psychol. Psychother. 2015, 44, 97-105. [CrossRef]

12. He, J.; Ma, H.; Barthels, F.; Fan, X. Psychometric properties of the Chinese version of the Düsseldorf Orthorexia Scale: Prevalence and demographic correlates of orthorexia nervosa among Chinese university students. Eat. Weight Disord. 2019, 24, 453-463. [CrossRef]

13. Varga, M.; Thege, B.K.; Dukay-Szabó, S.; Túry, F.; van Furth, E.F. When eating healthy is not healthy: Orthorexia nervosa and its measurement with the ORTO-15 in Hungary. BMC Psychiatry 2014, 14, 59. [CrossRef] [PubMed]

14. Parra-Fernandez, M.L.; Rodríguez-Cano, T.; Onieva-Zafra, M.D.; Perez-Haro, M.J.; Casero-Alonso, V.; Muñoz Camargo, J.C.; Notario-Pacheco, B. Adaptation and validation of the Spanish version of the ORTO-15 questionnaire for the diagnosis of orthorexia nervosa. PLoS ONE 2018, 13, e0190722. [CrossRef] [PubMed]

15. Bauer, S.M.; Fusté, A.; Andrés, A.; Saldaña, C. The Barcelona Orthorexia Scale (BOS): Development process using the Delphi method. Eat. Weight Disord. 2019, 24, 247-255. [CrossRef] [PubMed]

16. Brytek-Matera, A.; Krupa, M.; Poggiogalle, E.; Donini, L.M. Adaptation of the ORTHO-15 test to Polish women and men. Eat. Weight Disord. 2014, 19, 69-76. [CrossRef] [PubMed]

17. Missbach, B.; Dunn, T.M.; König, J.S. We need new tools to assess Orthorexia Nervosa. A commentary on "Prevalence of Orthorexia Nervosa among College Students Based on Bratman's Test and Associated Tendencies.". Appetite 2017, 108, 521-524. [CrossRef] [PubMed]

18. Bratman, S. Health Food Junkies: Overcoming the Obession with Healthful Eating; Broadway Books: Portland, OR, USA, 2000.

19. Stochel, M.; Kozik, M.J.; Zejda, J.; Hyrnik, J.; Jelonek, I.; Siwiec, A. Validation of ORTO-15 Questionnaire in the group of urban youth aged 15-21. Psychiatr. Pol. 2015, 49, 119-134. [CrossRef] [PubMed]

20. Haddad, C.; Obeid, S.; Akel, M.; Honein, K.; Akiki, M.; Azar, J.; Hallit, S. Correlates of orthorexia nervosa among a representative sample of the Lebanese population. Eat. Weight Disord. 2019, 24, 481-493. [CrossRef]

21. Fidan, T.; Ertekin, V.; Isikay, S.; Kirpinar, I. Prevalence of orthorexia among medical students in Erzurum, Turkey. Compr. Psychiatry 2010, 51, 49-54. [CrossRef]

22. Parra-Fernández, M.-L.; Rodríguez-Cano, T.; Onieva-Zafra, M.-D.; Perez-Haro, M.J.; Casero-Alonso, V.; Fernández-Martinez, E.; Notario-Pacheco, B. Prevalence of orthorexia nervosa in university students and its relationship with psychopathological aspects of eating behaviour disorders. BMC Psychiatry 2018, 18, 364. [CrossRef]

23. Aksoydan, E.; Camci, N. Prevalence of orthorexia nervosa among Turkish performance artists. Eat. Weight Disord. 2009, 14, 33-37. [CrossRef]

24. Chard, C.A.; Hilzendegen, C.; Barthels, F.; Stroebele-Benschop, N. Psychometric evaluation of the English version of the Düsseldorf Orthorexie Scale (DOS) and the prevalence of orthorexia nervosa among a U.S. student sample. Eat. Weight Disord. 2018, 24, 275-281. [CrossRef]

25. Parra-Fernández, M.L.; Onieva-Zafra, M.D.; Fernández-Muñoz, J.J.; Fernández-Martínez, E. Adaptation and validation of the Spanish version of the DOS questionnaire for the detection of orthorexic nervosa behavior. PLoS ONE 2019, 14, e0216583. [CrossRef] [PubMed] 
26. Depa, J.; Schweizer, J.; Bekers, S.-K.; Hilzendegen, C.; Stroebele-Benschop, N. Prevalence and predictors of orthorexia nervosa among German students using the 21-item-DOS. Eat. Weight Disord. 2017, 22, 193-199. [CrossRef] [PubMed]

27. Parra-Fernandez, M.L.; Rodríguez-Cano, T.; Perez-Haro, M.J.; Onieva-Zafra, M.D.; Fernandez-Martinez, E.; Notario-Pacheco, B. Structural validation of ORTO-11-ES for the diagnosis of orthorexia nervosa, Spanish version. Eat. Weight Disord. 2018, 23, 745-752. [CrossRef] [PubMed]

28. Dunn, T.M.; Gibbs, J.; Whitney, N.; Starosta, A. Prevalence of orthorexia nervosa is less than $1 \%$ : Data from a US sample. Eat. Weight Disord. 2017, 22, 185-192. [CrossRef]

29. Bağci Bosi, A.T.; Camur, D.; Güler, C. Prevalence of orthorexia nervosa in resident medical doctors in the faculty of medicine (Ankara, Turkey). Appetite 2007, 49, 661-666. [CrossRef]

30. Asil, E.; Sürücüoğlu, M.S. Orthorexia Nervosa in Turkish Dietitians. Ecol. Food Nutr. 2015, 54, $303-313$. [CrossRef]

31. Corral, S.; González, M.; Pereña, J.S.N. Adaptación española del Inventario de trastornos de la conducta alimentaria. EDI-2: Inventario de Trastornos de la Conducta Alimentaria. Madrid:TEA. 1998. Available online: http://www.guiasalud.es/egpc/traduccion/ingles/conducta_alimentaria/completa/ apartado10/evaluacion.html\#b348 (accessed on 6 February 2019).

32. Castro-Zamudio, S.; Castro-Barea, J. Impulsividad y búsqueda de sensaciones: Factores asociados a síntomas de anorexia y bulimia nerviosas en estudiantes de secundaria. Escr. Psicol. Psychol. Writ. 2016, 9, 22-30. [CrossRef]

33. Garner, D.M. Eating Disorder Inventory 2: Professional Manual; Tea Ediciones; Psychological Assessment Resources: Madrid, Spain, 1991.

34. Barthels, F.; Meyer, F.; Huber, T.; Pietrowsky, R. Orthorexic eating behaviour as a coping strategy in patients with anorexia nervosa. Eat. Weight Disord. 2016, 22, 269-276. [CrossRef]

35. Donini, L.M.; Marsili, D.; Graziani, M.P.; Imbriale, M.; Cannella, C. Orthorexia nervosa: A preliminary study with a proposal for diagnosis and an attempt to measure the dimension of the phenomenon. Eat. Weight Disord. 2004, 9, 151-157. [CrossRef]

36. Hyrnik, J.; Janas-Kozik, M.; Stochel, M.; Jelonek, I.; Siwiec, A.; Rybakowski, J.K. The assessment of orthorexia nervosa among 1899 Polish adolescents using the ORTO-15 questionnaire. Int. J. Psychiatry Clin. Pract. 2016, 20, 199-203. [CrossRef] [PubMed]

37. Montagner, M.I.; Montagner, M.Â. Orthorexia nervosa: Cultural adaptation of ortho-15. Demetra 2014, 9, 533-548.

38. Varga, M.; Thege, B.K.; Dukay-Szabó, S.; Túry, F.; van Furth, E.F. When eating healthy is not healthy: Orthorexia nervosa and its measurement with the ORTO-15 in Hungary. BMC Psychiatry 2014, 14, 59. [CrossRef] [PubMed]

39. Lopes, R.; Melo, R.; Dias Pereira, B. Orthorexia nervosa and comorbid depression successfully treated with mirtazapine: A case report. Eat. Weight Disord. 2018, 24, 1-5. [CrossRef] [PubMed]

40. Hunter, J.D.; Crudo, D.F. Unintended Consequences of Restrictive Diets: Two Case Reports and a Review of Orthorexia. Clin. Pediatr. 2018, 57, 1693-1695. [CrossRef] [PubMed]

41. Luck-Sikorski, C.; Jung, F.; Schlosser, K.; Riedel-Heller, S.G. Is orthorexic behavior common in the general public? A large representative study in Germany. Eat. Weight Disord. 2019, 24, 267-273. [CrossRef] [PubMed]

42. Ramacciotti, C.E.; Perrone, P.; Coli, E.; Burgalassi, A.; Conversano, C.; Massimetti, G.; Dell'Osso, L. Orthorexia nervosa in the general population: A preliminary screening using a self-administered questionnaire (ORTO-15). Eat. Weight Disord. 2011, 16, e127-e130. [CrossRef] [PubMed]

43. Segura-Garcia, C.; Papaianni, M.C.; Caglioti, F.; Procopio, L.; Nisticò, C.G.; Bombardiere, L.; Ammendolia, A.; Rizza, P.; De Fazio, P.; Capranica, L. Orthorexia nervosa: A frequent eating disordered behavior in athletes. Eat. Weight Disord. 2012, 17, 226-233. [CrossRef]

44. Jerez, F.T.; Lagos, H.R.; Valdés-Badilla, P.; Pacheco, P.E.; Pérez, C.C. Prevalencia de conducta ortoréxica en estudiantes de educación media de Temuco. Rev. Chil. Nutr. 2015, 42, 41-44. [CrossRef]

45. Brytek-Matera, A.; Donini, L.M.; Krupa, M.; Poggiogalle, E.; Hay, P. Erratum to: Orthorexia nervosa and self-attitudinal aspects of body image in female and male university students. J. Eat. Disord. 2016, 4, 16. [CrossRef]

46. Oberle, C.D.; Samaghabadi, R.O.; Hughes, E.M. Orthorexia nervosa: Assessment and correlates with gender, BMI, and personality. Appetite 2017, 108, 303-310. [CrossRef] [PubMed] 
47. Herranz Valera, J.; Acuña Ruiz, P.; Romero Valdespino, B.; Visioli, F. Prevalence of orthorexia nervosa among ashtanga yoga practitioners: A pilot study. Eat. Weight Disord. 2014, 19, 469-472. [CrossRef] [PubMed]

48. Kinzl, J.F.; Hauer, K.; Traweger, C.; Kiefer, I. Orthorexia nervosa in dieticians. Psychother. Psychosom. 2006, 75, 395-396. [CrossRef] [PubMed]

49. Segura-Garcia, C.; Ramacciotti, C.; Rania, M.; Aloi, M.; Caroleo, M.; Bruni, A.; Gazzarrini, D.; Sinopoli, F.; De Fazio, P. The prevalence of orthorexia nervosa among eating disorder patients after treatment. Eat. Weight Disord. 2015, 20, 161-166. [CrossRef] [PubMed]

50. Kabaran, S.; Gezer, C. The risk of orthorexia nervosa for female students studying nutrition and dietetic. SDU J. Health Sci. Inst. 2013, 4, 14-22.

51. Catalina Zamora, M.L.; Bote Bonaechea, B.; García Sánchez, F.; Ríos Rial, B. Orthorexia nervosa. A new eating behavior disorder? Actas Esp. Psiquiatr. 2005, 33, 66-68. [PubMed]

52. Missbach, B.; Hinterbuchinger, B.; Dreiseitl, V.; Zellhofer, S.; Kurz, C.; König, J. When Eating Right, Is Measured Wrong! A Validation and Critical Examination of the ORTO-15 Questionnaire in German. PLoS ONE 2015, 10, e0135772. [CrossRef] [PubMed]

53. Roncero, M.; Barrada, J.R.; Perpiñá, C. Measuring Orthorexia Nervosa: Psychometric Limitations of the ORTO-15. Span. J. Psychol. 2017, 20, 41. [CrossRef]

54. Depa, J.; Barrada, J.; Roncero, M. Are the Motives for Food Choices Different in Orthorexia Nervosa and Healthy Orthorexia? Nutrients 2019, 11, 697. [CrossRef]

(C) 2019 by the authors. Licensee MDPI, Basel, Switzerland. This article is an open access article distributed under the terms and conditions of the Creative Commons Attribution (CC BY) license (http://creativecommons.org/licenses/by/4.0/). 